\title{
Reseña. Eugenia Brito, Ficciones del muro: Brunet, Donoso, Eltit. Santiago: Editorial Cuarto Propio, 2014.
}

Ficciones del muro, último libro de Eugenia Brito, quien esta vez aborda las narrativas de tres autores chilenos, Marta Brunet, José Donoso y Diamela Eltit, para intervenir desde una nueva mirada, al espacio de la casa y sus habitantes quienes alteran, resisten, precisamente a aquella suerte de alegoría nacional, que ha pretendido sumar un tipo de escritura tendiente a sacralizar su portentosa comunidad imaginada. El libro aborda cómo estos autores estropean la linealidad de una historia nacional oficial para resaltar la productividad de sus resistencias, capaces de saltar el muro de esa simetría artificial que intenta constituir una trama simbólica que justifique la hegemonía de nuestro presente. Brito, con su lectura, atenta contra aquella dinámica épica, al incursionar en los espacios alterados y alterables de estos tres autores.

El libro se plantea como una lectura del lugar de "la casa como el espacio de formación del imaginario cultural y simbólico del país" (13). La casa hacienda, la casa-fundo, pierde relevancia ante la casa-habitación, la casa-cocina-sureña donde se produce el desenlace en el que Brunet articula su desmontaje en "Piedra callada", así como el prostíbulo hundiéndose con sus residentes, personalidades nómades, que en El lugar sin límites, incomodan al modelo monolítico del desarrollo nacional. Lo mismo aquel lugar monstruoso del Obsceno pájaro de la noche, en el que habitan los temores y abominaciones de una historia no oficial, 
que obstinadamente irrumpe en el entramado de un diseño global para denostar su incómoda existencia, y que en su precaria designación, van delimitando su propia alteridad, haciendo resquebrajar el muro que separa su inhóspita relación. Del mismo modo, da cuenta del desplazamiento en la obra de Eltit que va desde la periferia en ruinas intervenida por la dictadura, en Por la Patria hacia el despliegue de la familia como núcleo traspasado por poderes dominantes en $E l$ cuarto mundo. Son lugares en los que habitan subjetividades viejas, pobres, travestis, incestuosas, todo un lumperío, habitantes de las piezas de atrás, del barrial cercano al centro de la ciudad, los que atraviesan puentes y umbrales que conectan e incomodan a la ilustre familia nacional. Ficciones del muro, en este sentido, recorre estos relatos, como el apremiante intento de traspasar muros que separan a esos desarrapados, subalternos, indios y mestizos de la historia chilena que con sus interpelaciones dan saltos, rasguñan y amenazan demoler el muro que separa su inaprehensible condición deseante de una establecida manifestación de una iconografía nacional. Todos ellos se reflejan contra el espejo que fragmenta un yo dominante, que tendrá la forma actual de un mercado iluminado por las luces de los anaqueles y los avisos publicitarios de una sociedad que resiste abrir espacios a aquellas desidentidades y paisajes que desordenan el entramado neoliberal. Es por ello que la lectura de Brito es un apuesta política que ve en estos tres narradores "una dura resistencia de las clases menos favorecidas de este país para sortear los problemas sociales impuestos por los poderes hegemónicos que estereotipan cuerpos y deslegitiman historias" (19), es la emergencia de una historia plural como "arqueología del inconsciente latinoamericano" (19).

La casa como espacio en construcción, siempre en riesgo, sujeto a transformaciones y desmontajes, agrupan a los personajes en ciertas definiciones, conectadas por puentes, espacios de visibilidad en que dominadores y dominados se encuentran, se diferencian y se materializan, alterándose mutuamente. Umbrales, márgenes en los cuales los personajes acechan, mostrando impúdicamente su diferencia, incomodando, alterando, enrojeciendo al yo dominador y falogocéntrico. La casa, en el sentido de estos tres autores, es 
productora de una cierta comunidad política desde donde los subalternos intervienen en el entramado de su desafiliación patriótica, para denostar su propia inconsistencia en el registro serial de una historia oficial.

La lectura que ofrece este libro se articula en la noción medular de subalternidad, planteada por Gramsci y posteriormente por Spivak, para reconocer el mecanismo relacional de fuerzas que conforman subjetividades carentes de interpelación, dominados por una correlación de fuerzas que les impide hablar, o al menos ser escuchados. Desde aquí, lo que la autora destaca es la capacidad de resistencia de los personajes de estos tres autores donde, desde esta subordinación, son capaces de alterar el orden de esta jerarquía y provocar trizaduras en el muro que los separa y que al mismo tiempo constituye su propia circunscripción en su marginada representación. Esta dinámica es observada en Brunet en las relaciones genéricas y patronales, así como en Donoso con la alteración de los códigos sexuales que remecen el tranquilo espejo en el que se reconocen y desconocen los personajes, la monstruosidad de la otredad a los ojos de una burguesía aterrada por el otro, y en Eltit en la producción de un habla destrabada de comunidades insurgentes que habitan lo inhabitable, comunidades inimaginadas que incitan mediante su descontento el fracaso de un modelo político y social.

Uno de los puntos centrales de la lectura de Brito es la constatación de la movilidad de los personajes y sus construcciones que van fragmentando, movilizando la narración y delineando en estas relaciones la silueta desdibujada de nuevas subjetividades. Esta condición es esencial para entender que la mera inversión no es suficiente para modificar las relaciones de dominación, el caso más evidente es el de Humo hacia el Sur, otra de las obras de Brunet analizadas en este libro, donde la protagonista Batilde, convertida en una mujer fálica, se apropia del espacio masculino, habitando una casa-imagen dominante y que en la novela se clausura a través del fuego, evidencia de la imposibilidad de un matriarcado oligárquico, que sucumbe ante el peso de un desarrollo liberal de apertura económica de un capitalismo incipiente. La potencia de los personajes 
radica en su inaprehensibilidad, en sus prácticas, lenguajes, gestos que dificultan su control. Es el fracaso de la sustitución de la mujer por su correlato masculino, denunciando con ello que la mera inversión como estrategia sería insuficiente para refundar una nueva forma de organización comunitaria.

En el análisis que la autora hace de la obra de Donoso, tenemos cómo la casa-prostíbulo, hundiéndose en el Lugar sin límites, representa la fragilidad y desmoronamiento de un mundo amenazado por un poder, personificado en Cruz, dueño del pueblo, y también Pancho, ambos significantes masculinos que proyectan un orden específico y donde la Manuela se las arregla para alterar los mecanismos identificatorios y promover pulsiones dislocadoras. Para Brito, siguiendo a Derrida, la Manuela posee la capacidad de alterar los signos y sus significaciones, llevándolos a sus bordes, "el poder deconstructor de la Manuela, desde su lugar oprimido, consiste en descentrar identidades, horadando sus máscaras y el falso aparato ideológico que las sustenta" (57) La Manuela es el sujeto subalterno que altera y se desenmarca de las identidades designadas por un poder colonial. De ahí que el travestismo se articula como desmontador de un poder logocéntrico y occidental para dar paso a una desidentidad destrabada y movediza de una poscolonialidad.

Del mismo modo, El obsceno pájaro de la noche para Brito vendría a ser la crítica que devela al mundo dominador, diseñador de una modernidad que se hará mercado, hipermercado, que clasificará las vidas y las cosas en el estante para su venta, y donde lo feo, lo marginal y sus historias y prehistorias deterioran y estropean el fabuloso escenario moderno. La escritura, en este sentido, encerraría el tormentoso horror hacia los propios márgenes, zonas de una periferia al acecho, enemigo omnipresente en todas las otredades. "Encierra la verdad de un terror: terror del sinsentido, porque el laberinto que lo forma y el archivo de saberes que lo va armando no pueden precisar la forma ni la fuerza de ese exceso o desborde chileno y latinoamericano." (100)

A diferencia de la casa del Lugar sin límites como infierno, como no lugar que denuncia una frontera amenazante, la casa en el Obsceno pájaro de la noche 
es un laberinto trazado por la escritura, un relato que surge del asombro de Humberto Peñaloza ante los monstruos, oprimidos y marginales. Son relatos que dan cuenta de las pesadillas del patrón, quien teme que mientras duerma, en la oscuridad de la noche, se abrirán los cerrojos de su habitación para dar paso a aquellos que están más allá; distancia identitaria siempre en riesgo, y que amenaza con confrontar la mirada, cara a cara con su otro deformado por su propia semblanza.

Para Brito, el narrador de este relato nos muestra en la figura del mudito, la identificación del personaje con las construcciones políticas dominantes, que en su afán de adquirir un nombre, construye el relato delirante de su propia destrucción. Es la historia latinoamericana que para la autora constituye "la angustia blanca de perder su superioridad, enfrentándose a un modo de existencia que confronta la suya" (93).

A diferencia de lo planteado en Brunet y Donoso donde se perciben los personajes y sus marginalidades desde una cierta autoridad, como representaciones de un reverso innombrable que una burguesía pretende exorcizar mediante su aislamiento, en el análisis de las novelas de Eltit irrumpe la materialidad sonora de una voz silenciada, donde el ejercicio críptico de sus difamaciones se dan paso entre sitios de una periferia provocativa, capaz de alterar no solo el lugar que le ha sido asignado, sino de minar los trazos de representación y hacer sucumbir la monolítica autoridad de un orden cultural y semiótico ahora en disputa. Destaca cómo los personajes de Por la patria, privados de la retórica embadurnada de poder, verdad y belleza que certifican su dominio en el reflejo fáctico de lo totalitario, se abren espacio en la casa, lugar de conformación femenina asediada por el brutal riesgo de intervención, y que se abre hacia el bar, para continuar contaminando los espacios reservados para un repertorio masculino, con un papel asignado de antemano y con la carga simbólica y cultural que lo sustenta. En Eltit, estos lugares donde cabe destacar al mismo tiempo tanto al erial como al útero, son lugares de conformación de nuevas significaciones y afiliaciones que intentan recombinar sus onerosos reflejos, 
sombras y diagramaciones desestabilizadoras de una polis. Es por ello que la autora reconoce en la propuesta de Bhabha del tercer espacio como herramienta teórica para pensar estos desplazamientos, como lugar no tramado, pero plenamente narrado como posibilidad y potencia vivificante. Lugares móviles para sujetos nómadas "que se desplazan, [...]de contexto en contexto, para llegar a generar una movilidad dual, a ratos servil, a ratos vengativa, odiosa, pero con ciertas posibilidades de generar una malla semiótica que embadurne los sentidos 'europeos', haciéndolos aparecer absurdos y paradojales” (94).

La autora da cuenta en El cuarto mundo cómo la casa-útero es el lugar donde se gestan las coordenadas culturales y políticas que definen y delimitan los sujetos y al mismo tiempo la casa habitación donde se desarrolla la trama en una casa periférica, situada en el margen, lo que en conjunto permite conectar las pulsiones de los mellizos en el útero con el objeto material que es el libro que va a la venta, como el relato latinoamericano "escrito sobre la periferia y a partir de ella" (128), lo que vendría a inaugurar una preocupación por el neoliberalismo y su relación con Latinoamérica, puesta en circulación en el mercado global, con su dependencia social y económica.

Tanto en Por la patria como en El cuarto mundo, ahora es esa boca descarriada la que hablará de ella misma, es su pulsión resistente la que amenaza con multiplicarse en infinitas formas desaprendidas de una heroica gesta nacional. Las que horadan el muro que produce una endémica separación con el "escenario político-militar y su carga de opresión y muerte" (109) En este sentido, el golpe a la lengua, denunciado por Patricio Marchant, como condición establecida por la dictadura, no es suficiente para impedir buscar nuevas formas del decir, obstaculizando el proceso de decantación iconoclasta del mercado y su globalización, posibilitando la emergencia de "una colectividad que va a desear romper el orden militar, hegemónico, y que, desde esa inversión va a poder generar un código secreto de unión y resistencia" (114).

Finalmente, este libro tiene la virtud de recorrer obras de tres autores en momentos distintos de nuestra narrativa local, y a pesar de indagar en novelas 
ampliamente investigadas, supo dar un vuelco en la mirada, pronosticando que en todas ellas podemos vislumbrar los rastros de una contrahistoria, que en la escritura es posible abrir la palabra rebelde, asediada por proyectos simbólicos nacionales. Reconocer la tozudez de aquellos otros, en palabras de Brito: "Ni más ni menos ellos son lo anómalo y no visto: la dura historia de la periferia chilena, que busca, a su manera, la liberación de las múltiples colonizaciones y de los 'amos' que han insistido por siglos en abusar de ella" (99). 